\title{
Cancer Chemoprevention Using Nanotechnology-Based Approaches
}

OPEN ACCESS

Edited by:

Katrin Sak

NGO Praeventio, Estonia

Reviewed by:

Marcello Locatelli,

Università degli Studi G. d'Annunzio

Chieti e Pescara, Italy

Mariangela Garofalo,

University of Padova, Italy

*Correspondence:

Sunil Prabhu

sprabhu@westernu.edu

Specialty section:

This article was submitted to Pharmacology of Anti-Cancer Drugs,

a section of the journal

Frontiers in Pharmacology

Received: 19 December 2019

Accepted: 05 March 2020

Published: 03 April 2020

Citation:

Desai $P$, Thumma NJ, Wagh PR, Zhan S, Ann D, Wang J and Prabhu S (2020) Cancer Chemoprevention Using Nanotechnology-Based Approaches. Front. Pharmacol. 11:323. doi: 10.3389/fphar.2020.00323

\author{
Preshita Desai ${ }^{1}$, Naga Jyothi Thumma ${ }^{1}$, Pushkaraj Rajendra Wagh ${ }^{1}$, Shuyu Zhan ${ }^{1,2}$, \\ David Ann ${ }^{3}$, Jeffrey Wang ${ }^{1}$ and Sunil Prabhu ${ }^{1 *}$ \\ ${ }^{1}$ Department of Pharmaceutical Sciences, College of Pharmacy, Western University of Health Sciences, Pomona, CA, \\ United States, ${ }^{2}$ Department of Pharmaceutics, College of Medicine, Jiaxing University, Jiaxing, China, ${ }^{3}$ Department of \\ Diabetes and Metabolic Diseases Research, Beckman Research Institute, City of Hope, Duarte, CA, United States
}

Cancer research in pursuit of better diagnostic and treatment modalities has seen great advances in recent years. However, the incidence rate of cancer is still very high. Almost $40 \%$ of women and men are diagnosed with cancer during their lifetime. Such high incidence has not only resulted in high mortality but also severely compromised patient lifestyles, and added a great socioeconomic burden. In view of this, chemoprevention has gained wide attention as a method to reduce cancer incidence and its relapse after treatment. Among various stems of chemoprevention research, nanotechnology-based chemoprevention approaches have established their potential to offer better efficacy and safety. This review summarizes recent advances in nanotechnology-based chemoprevention strategies for various cancers with emphasis on lung and bronchial cancer, colorectal, pancreatic, and breast cancer and highlights the unmet needs in this developing field towards successful clinical translation.

Keywords: chemoprevention, nanotechnology, targeted delivery, efficacy, relapse

\section{INTRODUCTION}

Cancer poses a severe socioeconomic impact all over the world. As per the American Cancer Society, over 1,762,450 new cancer cases and about 606,880 cancer related deaths are estimated in the United States alone in 2019 (average of 4,830 new cases and 1,660 deaths per day) (American Cancer Society, 2019a). Late/limited diagnostic opportunities, faster progression, limited treatment options with severe toxicities, and frequent relapse are the key reasons for high cancer fatality and is an alarming concern despite extensive research conducted in this field and available clinical treatments thus far. Therefore, alternatives like cancer chemoprevention, which focus on reducing cancer incidence and/or relapse, are gaining wide attention in recent years. Cancer chemoprevention can be looked upon as a strategy designed to minimize and delay the incidence, progression, or relapse of cancer. The objective is to interfere with the process of carcinogenesis so as to arrest or substantially retard the growth of precancerous lesions to reduce cancer incidence (Patterson et al., 2013).

Over the decades, literature reports few hundreds of molecules to elicit such chemopreventive potential and among them the widely reported drug classes are nonsteroidal anti-inflammatory drugs or NSAIDS (e.g., aspirin, ibuprofen, etc.); antioxidants [curcumin, ferulic acid, resveratrol, ellagic acid, epigallocatechin-3-gallate (EGCG), etc.]; extracts from natural origin (tea, wheat bran, etc.); minerals and ions (calcium, zinc, etc.). However, very few have been clinically approved under 
the broader umbrella of chemoprevention strategies with a listed use to treat or mitigate risk of precancerous lesions (Patterson et al., 2013). Evidently, the clinical success of these actives is restricted due to drug delivery challenges. Hence, use of smart nano drug delivery systems ensuring in vivo absorption and transportation of such actives at chemoprevention sites using passive and active targeting approaches is gradually coming on the forefront (Siddiqui et al., 2012; Desai et al., 2019a; Desai et al., 2019b). Though nanochemoprevention research is in its infancy, its potential is evident from increasing research in the field and reported scientific literature. This review summarizes recent advances in this niche field and highlights the unmet needs towards successful clinical translation.

\section{Role of Nanotechnology in Chemoprevention}

Nanotechnology-based products broadly refer to nanoformulation comprising of particles $\leq 100 \mathrm{~nm}$ and from literature perspective those $<1000 \mathrm{~nm}$ (Jeevanandam et al., 2018). Such nanoscale size elicits superior properties to these drug carrier system from absorption, targeting, and safety aspect which are summarized in Figure 1 (modified from Desai et al., 2019a). Briefly, the overall drug efficacy and safety depend upon its intrinsic potency and variable factors like drug pharmacokinetics, toxicity, targeted delivery, and stability. Nanotechnology-based drug carriers successfully enhance these variable properties and thereby increase drug efficacy. Further, implementation of nanotechnology-based formulation in cancer prevention and therapy becomes very important in view of chemotherapy-associated side effects as they can provide an opportunity for possible dose reduction and drug targeting which can additionally enhance drug safety by minimizing offtarget toxicities. Nanoformulations can be broadly classified based on their excipient composition and are depicted in
Figure 2 (modified from Desai et al., 2019a), which can be polymeric, lipid, carbon based, inorganic, or combinations thereof (Muqbil et al., 2011; Siddiqui et al., 2012; Miller et al., 2016).

\section{Nanotechnology-Based Chemoprevention Approaches Lung and Bronchial Cancer}

Lung and bronchial cancer is the leading cause of cancer-related deaths in the United States (American Cancer Society, 2019a). The key carcinogenesis factor is long-term tobacco use while other factors include exposure to radon gas, asbestos, air pollution, and second-hand smoke (Office on and Health, 2006; Gemine et al., 2019). The long-term prevention strategy is smoking withdrawal but the cancer risk of prior or current smoking population remains high. The average age of cohort diagnosed with lung cancer is 50-75 years with majority of patients being 65 years or older. The existing treatment modalities (surgery, chemotherapy, or radiation therapy) have succeeded in elongating life expectancy but in most cases, the disease is incurable leading to high fatality (American Cancer Society, 2019b; Farr et al., 2019; Mieras et al., 2019). Chemoprevention has been explored for management of lung cancer using natural or synthetic compounds to inhibit progression or suppress, reverse tumor growth. To overcome hydrophobicity and low bioavailability of such actives, nanotechnology-based approaches have been investigated. One such hydrophobic active is luteolin from green vegetables. Majumdar et al. developed nanoluteolin comprising luteolin nanocapsules with water-soluble polymer. They reported enhanced chemoprevention efficacy with nanoluteolin in an in vitro setting using cell lines of lung cancer (H292) and squamous carcinoma head and neck cancer (Tu212) and similar significant efficacy was observed in a tumor xenograft model (Emory Health

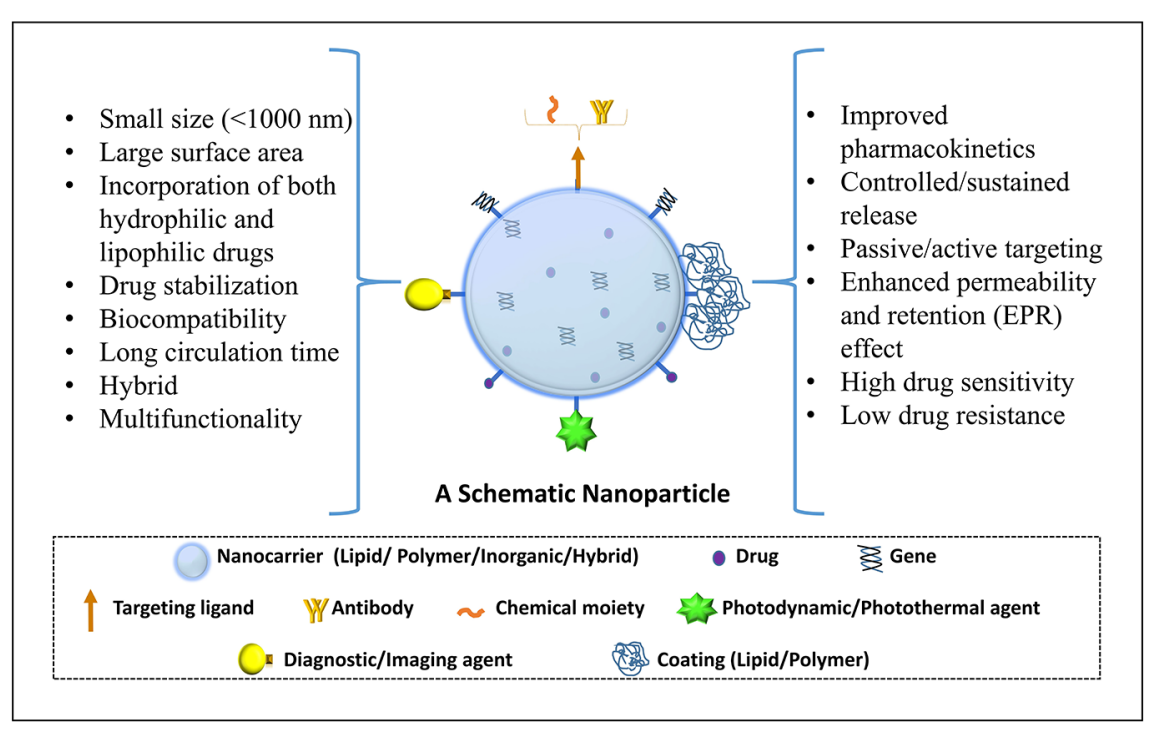

FIGURE 1 | Schematic representation of a functional nanocarrier and its superior properties. 


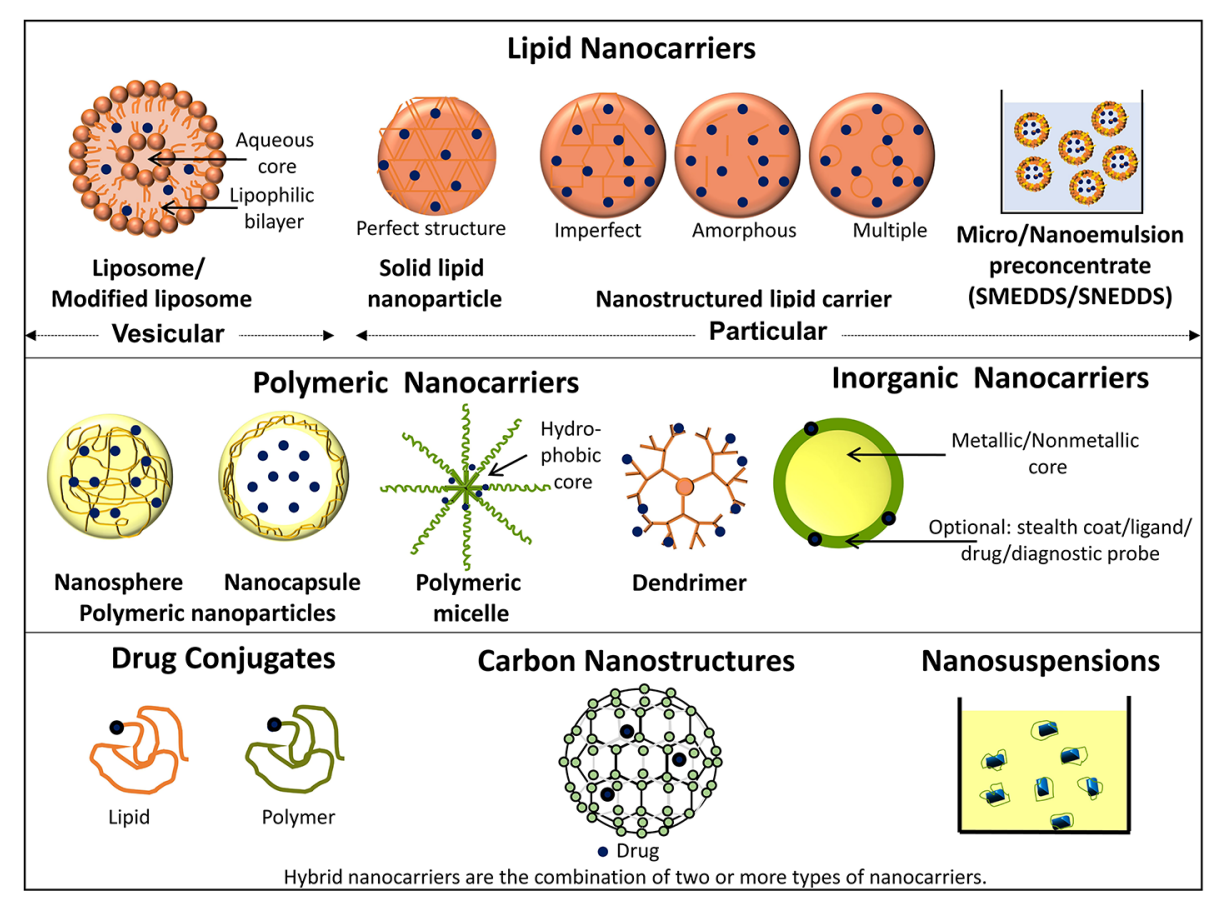

FIGURE 2 | Schematic representation depicting types of nanocarriers.

Sciences, 2014; Majumdar et al., 2014). In another study, to enhance the solubility of chemopreventive antioxidant resveratrol, hydroxypropyl- $\beta$-cyclodextrin complex was developed for intranasal delivery. A 25-day in vivo study in $\mathrm{A} / \mathrm{J}$ mice lung carcinogenesis model demonstrated $27 \%$ reduction in tumor multiplicity with $45 \%$ lower tumor volume confirming the efficacy of the developed formulation. Such a formulation approach is anticipated to enhance the drug bioavailability and hence has great potential in future clinical studies (Monteillier et al., 2018). In another study, lipid nanoparticles (NPs) of three chemopreventive drugs $\mathrm{N}$-acetyl-L-cysteine, phenethyl isothiocyanate, and resveratrol were developed and their chemopreventive potential was assessed in bronchial epithelial cells. The study revealed significant enhancement in reducing the DNA fragmentation due to cigarette smoke with resveratrol lipid NPs confirming its potential to increase efficacy of lipophilic drug. However, the results were not significant with hydrophilic drug $\mathrm{N}$-acetyl-L-cysteine indicating that appropriate selection of drug and NPs combination is very essential in development of successful chemoprevention strategy (Pulliero et al., 2015). Similarly, to enhance the in vivo performance of well-reported natural chemopreventive agent naringenin, polycaprolactone NPs of naringenin were developed with hyaluronic acid as an active targeting agent. The developed NPs were proven to show enhanced inhibitory potential against lung cancer cell line A549 but was found to be safe against J774 macrophage cell line confirming both enhanced efficacy and safety. The in vivo studies using urethane-induced lung cancer in rat model established significant tumor inhibitory activity confirming the in vivo drug targeting (Parashar et al., 2018). Further, a natural antioxidant, curcumin has shown a strong lung cancer stem cells suppression potency but its poor bioavailability makes it ineffective in vivo. Therefore, enhancing the bioavailability of drug is a potential approach and various NPs like lipid, polymer, liposomes have been reported to do so. Other promising agents such as vitamin A (retinoids or carotenoids), isothiocyanates, green tea extract, and bitter melon extract have also shown promise in head and neck cancer and their efficacy could be improvised to clinical significance using nanotechnology-based approaches.

\section{Colorectal Cancer}

Colorectal cancer is the second common cause of cancer related deaths in the United States (Americancancersociety, 2019a). Most of the colon cancers develop from the noncancerous adenomatous polyps, but when left untreated these polyps can become cancerous (Testa et al., 2018). Though surgical resection is the primary line of treatment, uncertainty in the detection methods and poor compliance leads to development of metastatic cancer and relapse (Vernon, 1997). Hence, prevention of polyp formation and development can be considered as a first line prevention approach.

For colon cancer chemoprevention, NSAIDs are most widely used (U.S. Preventive Services Task Force, 2007; Alizadeh et al., 2012; Drew et al., 2016; Pan et al., 2018). The epidemiological studies show that among all the NSAIDs, aspirin is the most promising agent in reducing adenomatous cancer recurrence due to the availability of remarkably consistent data with no cardiovascular risk and minimal gastrointestinal toxicity (Umezawa et al., 2019). Further, aspirin has also received a Grade B recommendation by the (U.S. Preventive Services Task Force, 2016) for its use as a chronic prophylaxis agent for colorectal cancer 
(Dehmer et al., 2015). Although it has been proved that aspirin alone or in combination have colon chemopreventive activity, nanoencapsulation of aspirin can further potentiate the efficacy with decreased dose. Chaudhary et al. studied chemopreventive effect of a mixture of aspirin, folic acid, and calcium on azoxymethane treated 7-week-old male Sprague-Dawley rats. The polymeric nanocapsules of drug combination prepared using polylactic-co-glycolic acid (PLGA) 50:50 polymer showed 1.7-fold more effective in chemoprevention than their unmodified counterpart regimen (Prabhu et al., 2007; Chaudhary et al., 2011). Celecoxib is another NSAID which is being widely explored in clinical setting for its chemoprevention potential but offers cardiotoxicity and pharmacokinetic variability (Solomon et al., 2005). Studies show that polymeric NPs of celecoxib prepared using ethyl cellulose with sodium caseinate/bile salt, lipid hybrid NPs, and microemulsions improved its bioavailability allowing reduction in dose, related cardiotoxicity, and crystallization (Margulis-Goshen et al., 2011; Tan et al., 2011; Morgen et al., 2012). Naturally derived phytochemicals are widely studied as potential chemopreventive agents for their pleiotropic effects and non-toxicity (Thomasset et al., 2007; Zubair et al., 2017; Wong et al., 2019). Curcumin has shown efficient chemoprotective activity in intestinal and colon cancer, but has minimal water solubility, poor absorption, and low bioavailability. To overcome this issue, curcumin-whey protein nanocapsules were developed that not only showed $>70 \%$ release in $48 \mathrm{~h}$ but also exhibited enhanced cell internalization and bioavailability. (Jayaprakasha et al., 2016). In another study, it was revealed that curcumin encapsulated in polymeric nanocarrier improved the solubility of curcumin and showed significantly reduced number of tumors, less structural abnormalities and beta-catenin (a key intracellular messenger in gastrointestinal tract malignancies) in curcumin NPs-treated group when compared to the curcumin (Alizadeh et al., 2012).

\section{Pancreatic Cancer}

Pancreatic cancer is the third leading cause of all cancer-related deaths in the United States (American Cancer Society, 2019a). Late diagnosis, faster progression, low 5-year survival rate (merely 9\%), and high risk of relapse make pancreatic cancer treatment and management challenging despite available firstline drug treatment involving use of gemcitabine combinations and Folfirinox ${ }^{\circledR}$ (a drug cocktail of fluorouracil, leucovorin, irinotecan, and oxaliplatin) (Rahman et al., 2017; Malatesta et al., 2018; American Cancer Society, 2019a; Desai et al., 2019a; Desai et al., 2019b). Hence, chemoprevention has gained wide attention as an alternative strategy to control the occurrence and relapse.

Lipid nanocarriers have been widely investigated for this purpose, Prabhu et al. developed solid lipid NPs comprising aspirin, curcumin, and free sulforaphane as a nanocombination chemoprevention platform. The developed formulation showed significant enhancement in inhibition in Panc- 1 and Mia PaCa-2 cell line models and synergism due to use of multiple drugs eliciting chemoprevention activity via variable mechanisms. Further, an in vivo chemoprevention study using LSL-Kras ${ }^{\mathrm{G} 12 \mathrm{D} /+} ; \mathrm{Pdx}-1^{\mathrm{Cre} /+}$ transgenic mice indicated significant reduction in tumor incidence with the combination nanoformulation compared to control (Sutaria et al., 2012; Thakkar et al., 2013). In another study, self micro-emulsifying drug delivery system (SMEDDS) of classical antihistaminic drug loratadine and sulforaphane was reported with enhanced oral bioavailability and chemoprevention potential in Panc-1 and Mia PaCa-2 PC cell lines (Desai et al., 2019b). Based on similar rational liposomes, dendrimers, micelles of potent chemopreventive phytochemical like curcumin, ellagic acid, etc. have been reported to show enhanced inhibition in pancreatic cancer cell lines and their application can be extended for pancreatic cancer chemoprevention (Song et al., 2011; Kesharwani et al., 2015; Wei et al., 2017).

Gene therapy has also been investigated for prevention purpose and various siRNAs, viral vectors have been studied (Lebedeva et al., 2008; Sarkar et al., 2014; Lei et al., 2017). In an interesting study by Fisher et al., replication incompetent adenoviruses capable of delivering a melanoma differentiation associated gene-7/Interleukin-24 (mda-7/IL-24) in presence of perillyl alcohol was developed. The formed nanoviral vector exhibited synergistic inhibition of pancreatic cancer cells with antitumor "bystander" response leading to suppression of primary as well as distant tumor growth. Hence, this strategy can be considered as a future clinical solution for chemoprevention and treatment and can also play a critical role in arresting pancreatic cancer relapse (Lebedeva et al., 2008; Sarkar et al., 2014).

\section{Breast Cancer}

Breast cancer has highest incidence and is listed to be the fourth leading cause of cancer-associated deaths in the United States (American Cancer Society, 2019a). Though chemotherapy using drugs like selective estrogen receptor modulators (tamoxifen, raloxifene, etc.), aromatase inhibitors (exemestane, anastrozole, letrozole, etc.) have shown treatment efficacy, very high incidence of breast cancer warrants development of promising preventive strategies (Ales-Martinez et al., 2015; Decensi et al., 2015; Locatelli et al., 2018). In recent years, natural products and some antineoplastic agents such as tamoxifen or raloxifene have displayed potential in chemoprevention of breast cancer (Mitra and Dash, 2018; Uramova et al., 2018). However, to enhance drug stability, achieve sustained drug release and to circumvent side effects, delivery of these agents using nanoformulations has been warranted. According to the reports, various nanoformulations such as liposome, nanofibers, nanocapsules, and NPs have been developed and investigated for prevention of breast cancer cells proliferation, breast cancer recurrence and metastasis after chemotherapy (Li et al., 2011; Roy et al., 2015; Shirode et al., 2015; Ding et al., 2016). A polymeric NPs formulation of curcumin (NanoCurc) was designed and studied to significantly attenuate incidence of mammary tumors in a rodent chemical carcinogenesis model, confirming its breast cancer chemoprevention potential in at-risk populations (Chun et al., 2012). In another study, the composite polycaprolactone/silk fibroin nanofibrous scaffolds loaded with titanocene were developed and reported to have potential for preventing the proliferation of breast cancer cells (Laiva et al., 2015). Interestingly, dietary soy isoflavones 
(genistein, etc.) have shown potential in reducing cancer incidence and their nanoformulations like PEGylated silica NPs, Chitosan NPs have shown significant enhancement in breast and cervical cancer inhibition (Sarkar and Li, 2003; Cai et al., 2017; Pool et al., 2018). Also, poly (ethylene glycol)modified chitosan NPs were synthesized to encapsulate and deliver small interfering RNA (siRNA). The siRNA loaded NPs showed $4 \mathrm{~T} 1$ cell inhibition both in vitro and in vivo ensuring its efficacy in reduction of tumor growth and metastasis (Sun et al., 2016). Wan et al. developed the lapatinib-loaded human serum albumin NPs that exhibited a core-shell structure with stealth properties preventing brain metastasis from triple-negative breast cancer (Wan et al., 2016). Interestingly, overcoming drug resistance and increasing cancer cell sensitivity towards drugs have also been investigated under this umbrella using a glycolipid-like nanocarrier encapsulating anti-tumor drug doxorubicin, which restricted drug resistance upon long-term use (Meng et al., 2019).

Hybrid NPs have also been explored for chemoprevention. Tran et al. developed the hyaluronic acid coated solid lipid NPs for co-delivery of ibuprofen and paclitaxel that resulted in synergistic inhibition on the proliferation of cancer cells (Tran et al., 2017). Zhang et al. designed a multifunctional hybrid nanomedicine integrating multiple FDA-approved modalities like radiotherapy, chemotherapy, photothermal therapy, and immunotherapy, which demonstrated elimination of the primary breast tumor and efficiently prevented tumor recurrence and metastasis to lung (Zhang et al., 2019b). Further, small peptide T4 (NLLMAAS) has been reported to inhibit tyrosine kinase, immunoglobulin, and epidermal growth factor homology-2 (Tie2), required for blood vessels reconstruction during tumor recurrence. To achieve this inhibition effectively and in targeted manner, selective NPs comprising dual-responsive amphiphilic peptide (mPEG1000K (DEAP)-AANNLLMAAS) were developed. The NPs were capable of releasing the peptide T4 under acidic tumor environment and could achieve targeted inhibition resulting in breast tumor relapse inhibition (Zhang et al., 2019a). In another study, nanographene oxide-methylene blue formulations in combination with photodynamic and photothermal treatment were reported to prevent breast tumor regrowth and metastasis to the liver, lung, and spleen (Dos Santos et al., 2018).

\section{Miscellaneous Cancers}

Chemoprevention has also been studied in other less common forms of cancers including but not limited to head, neck, skin, prostate, liver. Head and neck squamous cell carcinoma is a fast progressive form of cancer and oral cancer is highly prevalent subtype therein (Crooker et al., 2018). Recently, indigenous extracellular vesicles like exosomes, microvesicles, apoptic bodies derived from mammalian or tumor cells are gaining wide attention as chemopreventive and treatment tools. They have been recognized as valuable carriers for drugs like paclitaxel, RNAs, peptides, etc. and have shown potential in inhibiting of various types of cancers (Wang et al., 2017; Han et al., 2019; Rahbarghazi et al., 2019; Wu et al., 2019)
For the site-specific local treatment and chemoprevention of oral squamous cell carcinoma, several polymeric drug delivery systems have been developed using nanotechnology which has shown enhanced activity (Desai, 2018; Ketabat et al., 2019). Some studies include drugs nanoformulations such as naringenin NPs, ellagic acid chitosan NPs, which showed significant enhancement in both bioavailability and efficacy (Arulmozhi et al., 2013; Sulfikkarali et al., 2013; Desai, 2018). In addition, cisplatin when encapsulated in polymeric micelles was reported to eliminate cisplatin induced nephrotoxicity (Endo et al., 2013; Desai, 2018). Further, PEGylated nanoliposomes of paclitaxel, resveratrol, and 5-fluorouracil were reported to show controlled drug release in inhibition of head and neck carcinoma and liposomal formulation of irinotecan (Onivyde ${ }^{\circledR}$ ) has already been in market for pancreatic cancer management (Nie et al., 2011; Desai, 2018). Another natural chemopreventive agent, salvianolic acid B was encapsulated in phospholipid complex loaded NPs and the studies showed significant increase in intracellular uptake and improved cell inhibition when compared to drug for head and neck carcinoma (Li et al., 2016).

In the past few years, green tea and its major polyphenol, catechin have been demonstrated to superior chemoprevention activity on multiple cancer types mainly because of their antioxidant/pro-oxidant properties (Naponelli et al., 2017). To improve the drug's bioavailability, stability, and tumor selectivity, nanotechnology-based drug delivery systems have been widely studied (Tyagi et al., 2017). To study the chemoprevention efficacy of combination, gold-conjugated green tea NPs were designed that demonstrated selective toxicity towards Ehrlich's Ascites Carcinoma and breast cancer cells MCF-7 and interestingly had hepatoprotective behavior against the tumorinduced cellular damage (Mukherjee et al., 2015). For prostate cancer prevention and therapy, targeted EGCG polymeric NPs were developed using a biocompatible polymer polylactic-coglycolic acid-polyethylene glycol-A (PLGA-PEG-A) which have a specific binding and high inhibitory action against prostate cancer cells via specific membrane antigen resulting in enhanced bioavailability, limited toxicity, and in turn enhanced efficacy (Sanna et al., 2017).

Hesperetin, a bio-flavonoid, plays a potential role in liver cancer management. To overcome it poor solubility, bioavailability, biocompatibility issues, hesperetin, loaded gold NPs were designed. These NPs demonstrated significantly higher in vivo prevention activity against lipid per-oxidation, hepatic cell damage in diethylnitrosamine-induced liver cancer model compared to the drug alone (Gokuladhas et al., 2016).

In the area of skin cancer prevention, nanotechnology-based drug formulation such as nanoemulsion of 5-fluorouracil, bromelain polymeric NPs using PLGA, solid lipid NPs of doxorubicin, 5-flurouracil have been reported (Bhatnagar et al., 2015; Shakeel et al., 2015; Ravikumar and Tatke, 2019). Use of NPs to enhance the skin deposition of chemopreventive agents is an ideal way to enhance the chemopreventive efficacy. Such examples include shell-enriched solid lipid NPs of 5-fluorouracil, curcumin-ceramide niososmes, etc. (Heenatigala Palliyage et al., 2019; Ravikumar and Tatke, 2019). NPs have also been 
developed and studied to elicit enhanced protection against UV radiation. Several studies including development of ultra-flexible NPs of an antioxidant diindolylmethane derivative, silver NPs, etc. (Boakye et al., 2016; Bagde et al., 2018).

\section{Regulatory, Clinical Insights, and Future Directions}

Application of nanotechnology in cancer chemoprevention has certainly proven its potential to deliver the drugs in more effective, safer, and targeted manner. The research in this area is further advancing towards development of nanovaccines for cancer prevention. Also, early detection techniques using nanoplatforms capable of identifying pre-malignant markers are gaining attention as a preventive measure and nanodevices comprising nanochips, nanodots, quantum dots, nanoshells, and nanotubes have been reported (Bentolila et al., 2009; Boisselier and Astruc, 2009; Larocque et al., 2009; Singh et al., 2018; Facciola et al., 2019; Kheirollahpour et al., 2019; Shen et al.,
2019). Despite of such advances in research, their bench-tobedside translation for cancer prevention has a long way to go owing to regulatory and clinical considerations. In this context, mainly NSAIDS, retinoids, cyclooxygenase inhibitors, etc. have shown clinical potential through randomized clinical studies. However, more concentrated efforts and well-planned studies with measurable clinical outcomes are warranted. Further, proving the safety of nanoformulations is an urgently needed aspect. In view of regulatory approval of nanotechnology-based products for cancer treatment and other conditions, we should expect the clinical translation of nanotechnology-based products for cancer chemoprevention in near future.

\section{AUTHOR CONTRIBUTIONS}

PD, JW, and SP conceived and proposed the idea. PD compiled the manuscript with support from NT, PW, SZ. DA, JW and SP reviewed and revised the manuscript.

\section{REFERENCES}

Ales-Martinez, J. E., Ruiz, A., Chacon, J. I., Lluch Hernandez, A., Ramos, M., Cordoba, O., et al. (2015). Preventive treatments for breast cancer: recent developments. Clin. Transl. Oncol. 17, 257-263. doi: 10.1007/s12094-014-1250-2

Alizadeh, A. M., Khaniki, M., Azizian, S., Mohaghgheghi, M. A., Sadeghizadeh, M., and Najafi, F. (2012). Chemoprevention of azoxymethane-initiated colon cancer in rat by using a novel polymeric nanocarrier-curcumin. Eur. J. Pharmacol. 689, 226-232. doi: 10.1016/j.ejphar.2012.06.016

American Cancer Society (2019a). Cancer statistics center, American Cancer Society. [Online]. Available: https://cancerstatisticscenter.cancer.org/\#!/ [Accessed 2019/12/12].

American Cancer Society (2019b). Key Statistics for Lung Cancer, American Cancer Society. [Online]. Available: https://www.cancer.org/cancer/lungcancer/about/key-statistics.html [Accessed 2019/12/12].

Arulmozhi, V., Pandian, K., and Mirunalini, S. (2013). Ellagic acid encapsulated chitosan nanoparticles for drug delivery system in human oral cancer cell line (KB). Colloids Surf. B B. 110, 313-320. doi: 10.1016/j.colsurfb.2013.03.039

Bagde, A., Mondal, A., and Singh, M. (2018). Drug delivery strategies for chemoprevention of UVB-induced skin cancer: A review. Photodermatol. Photoimmunol. Photomed. 34, 60-68. doi: 10.1111/phpp.12368

Bentolila, L. A., Ebenstein, Y., and Weiss, S. (2009). Quantum dots for in vivo smallanimal imaging. J. Nucl. Med. 50, 493-496. doi: 10.2967/jnumed.108.053561

Bhatnagar, P., Pant, A. B., Shukla, Y., Chaudhari, B., Kumar, P., and Gupta, K. C. (2015). Bromelain nanoparticles protect against 7,12-dimethylbenz[a] anthracene induced skin carcinogenesis in mouse model. Eur. J. Pharm. Biopharm. 91, 35-46. doi: 10.1016/j.ejpb.2015.01.015

Boakye, C. H. A., Patel, K., Doddapaneni, R., Bagde, A., Behl, G., Chowdhury, N., et al. (2016). Ultra-flexible nanocarriers for enhanced topical delivery of a highly lipophilic antioxidative molecule for skin cancer chemoprevention. Colloids Surf. B: B. 143, 156-167. doi: 10.1016/j.colsurfb.2016.03.036

Boisselier, E., and Astruc, D. (2009). Gold nanoparticles in nanomedicine: preparations, imaging, diagnostics, therapies and toxicity. Chem. Soc. Rev. 38, 1759-1782. doi: 10.1039/b806051g

Cai, L., Yu, R., Hao, X., and Ding, X. (2017). Folate Receptor-targeted Bioflavonoid Genistein-loaded Chitosan Nanoparticles for Enhanced Anticancer Effect in Cervical Cancers. Nanoscale Res. Lett. 12, 509-509. doi: 10.1186/s11671-017-2253-Z

Chaudhary, A., Sutaria, D., Huang, Y., Wang, J., and Prabhu, S. (2011). Chemoprevention of colon cancer in a rat carcinogenesis model using a

novel nanotechnology-based combined treatment system. Cancer Prev. Res. (Phila) 4, 1655-1664. doi: 10.1158/1940-6207.CAPR-11-0129

Chun, Y. S., Bisht, S., Chenna, V., Pramanik, D., Yoshida, T., Hong, S. M., et al. (2012). Intraductal administration of a polymeric nanoparticle formulation of curcumin (NanoCurc) significantly attenuates incidence of mammary tumors in a rodent chemical carcinogenesis model: Implications for breast cancer chemoprevention in at-risk populations. Carcinogenesis 33, 2242-2249. doi: $10.1093 /$ carcin/bgs 248

Crooker, K., Aliani, R., Ananth, M., Arnold, L., Anant, S., and Thomas, S. M. (2018). A Review of Promising Natural Chemopreventive Agents for Head and Neck Cancer. Cancer Prev. Res. (Phila) 11, 441-450. doi: 10.1158/19406207.CAPR-17-0419

Decensi, A., Thorat, M. A., Bonanni, B., Smith, S. G., and Cuzick, J. (2015). Barriers to preventive therapy for breast and other major cancers and strategies to improve uptake. Ecancermedicalscience 9, 595. doi: 10.3332/ecancer.2015.595

Dehmer, S. P., Maciosek, M. V., and Flottemesch, T. J. (2015). "U.S. Preventive Services Task Force Evidence Syntheses, formerly Systematic Evidence Reviews," in Aspirin Use to Prevent Cardiovascular Disease and Colorectal Cancer: A Decision Analysis: Technical Report. (Rockville (MD): Agency for Healthcare Research and Quality (US)).

Desai, P., Ann, D., Wang, J., and Prabhu, S. (2019a). Pancreatic Cancer: Recent Advances in Nanoformulation-Based Therapies. Crit. Rev. Ther. Drug Carrier Syst. 36, 59-91. doi: 10.1615/CritRevTherDrugCarrierSyst.2018025459

Desai, P., Thakkar, A., Ann, D., Wang, J., and Prabhu, S. (2019b). Loratadine selfmicroemulsifying drug delivery systems (SMEDDS) in combination with sulforaphane for the synergistic chemoprevention of pancreatic cancer. Drug Delivery Transl. Res. 9, 641-651. doi: 10.1007/s13346-019-00619-0

Desai, K. G. H. (2018). Polymeric drug delivery systems for intraoral site-specific chemoprevention of oral cancer. J. BioMed. Mater. Res. B Appl. Biomater. 106, 1383-1413. doi: 10.1002/jbm.b.33943

Ding, Q., Li, Z., Yang, Y., Guo, G., Luo, F., Chen, Z., et al. (2016). Preparation and therapeutic application of docetaxel-loaded poly(d,l-lactide) nanofibers in preventing breast cancer recurrence. Drug Deliv. 23, 2677-2685. doi: 10.3109/10717544.2015.1048490

Dos Santos, M. S. C., Gouvea, A. L., De Moura, L. D., Paterno, L. G., De Souza, P. E. N., Bastos, A. P., et al. (2018). Nanographene oxide-methylene blue as phototherapies platform for breast tumor ablation and metastasis prevention in a syngeneic orthotopic murine model. J. Nanobiotechnol. 16, 9. doi: 10.1186/ s12951-018-0333-6 
Drew, D. A., Cao, Y., and Chan, A. T. (2016). Aspirin and colorectal cancer: the promise of precision chemoprevention. Nat. Rev. Cancer 16, 173-186. doi: 10.1038/nrc.2016.4

Endo, K., Ueno, T., Kondo, S., Wakisaka, N., Murono, S., Ito, M., et al. (2013). Tumor-targeted chemotherapy with the nanopolymer-based drug NC-6004 for oral squamous cell carcinoma. Cancer Sci. 104, 369-374. doi: 10.1111/ cas. 12079

Facciola, A., Visalli, G., Lagana, P., La Fauci, V., Squeri, R., Pellicano, G. F., et al. (2019). The new era of vaccines: the "nanovaccinology". Eur. Rev. Med. Pharmacol. Sci. 23, 7163-7182. doi: 10.26355/eurrev_201908_18763

Farr, K. P., West, K., Yeghiaian-Alvandi, R., Farlow, D., Stensmyr, R., Chicco, A., et al. (2019). Functional perfusion image guided radiation treatment planning for locally advanced lung cancer. Phys. Imaging Radiat. Oncol. 11, 76-81. doi: 10.1016/j.phro.2019.08.007

Emory Health Sciences (2014). Nano-capsules show potential for more potent chemoprevention, [Online]. Available: https://www.sciencedaily.com/releases/ 2014/01/140108081219.htm [Accessed 2019/12/12]. ScienceDaily.

Gemine, R. E., Ghosal, R., Collier, G., Parry, D., Campbell, I., Davies, G., et al. (2019). Longitudinal study to assess impact of smoking at diagnosis and quitting on 1-year survival for people with non-small cell lung cancer. Lung Cancer 129, 1-7. doi: 10.1016/j.lungcan.2018.12.028

Gokuladhas, K., Jayakumar, S., Rajan, B., Elamaran, R., Pramila, C. S., Gopikrishnan, M., et al. (2016). Exploring the Potential Role of Chemopreventive Agent, Hesperetin Conjugated Pegylated Gold Nanoparticles in Diethylnitrosamine-Induced Hepatocellular Carcinoma in Male Wistar Albino Rats. Indian J. Clin. Biochem. 31, 171-184. doi: 10.1007/ s12291-015-0520-2

Han, L., Lam, E. W. F., and Sun, Y. (2019). Extracellular vesicles in the tumor microenvironment: old stories, but new tales. Mol. Cancer 18, 59. doi: 10.1186/ s12943-019-0980-8

Heenatigala Palliyage, G., Singh, S., Ashby, C. R.Jr., Tiwari, A. K., and Chauhan, H. (2019). Pharmaceutical Topical Delivery of Poorly Soluble Polyphenols: Potential Role in Prevention and Treatment of Melanoma. AAPS PharmSciTech 20, 250. doi: 10.1208/s12249-019-1457-1

Jayaprakasha, G. K., Chidambara Murthy, K. N., and Patil, B. S. (2016). Enhanced colon cancer chemoprevention of curcumin by nanoencapsulation with whey protein. Eur. J. Pharmacol. 789, 291-300. doi: 10.1016/j.ejphar.2016.07.017

Jeevanandam, J., Barhoum, A., Chan, Y. S., Dufresne, A., and Danquah, M. K. (2018). Review on nanoparticles and nanostructured materials: history, sources, toxicity and regulations. Beilstein J. Nanotechnol. 9, 1050-1074. doi: 10.3762/bjnano.9.98

Kesharwani, P., Xie, L., Banerjee, S., Mao, G., Padhye, S., Sarkar, F. H., et al. (2015). Hyaluronic acid-conjugated polyamidoamine dendrimers for targeted delivery of 3,4-difluorobenzylidene curcumin to CD44 overexpressing pancreatic cancer cells. Colloids Surf. B B. 136, 413-423. doi: 10.1016/j.colsurfb.2015.09.043

Ketabat, F., Pundir, M., Mohabatpour, F., Lobanova, L., Koutsopoulos, S., Hadjiiski, L., et al. (2019). Controlled Drug Delivery Systems for Oral Cancer Treatment-Current Status and Future Perspectives. Pharmaceutics 11, pii: E302. doi: 10.3390/pharmaceutics11070302

Kheirollahpour, M., Mehrabi, M., Dounighi, N. M., Mohammadi, M., and Masoudi, A. (2019). Nanoparticles and Vaccine Development. Pharm. Nanotechnol. 8, (1) 6-21. doi: 10.2174/2211738507666191024162042

Laiva, A. L., Venugopal, J. R., Karuppuswamy, P., Navaneethan, B., Gora, A., and Ramakrishna, S. (2015). Controlled release of titanocene into the hybrid nanofibrous scaffolds to prevent the proliferation of breast cancer cells. Int. J. Pharm. 483, 115-123. doi: 10.1016/j.ijpharm.2015.02.025

Larocque, J., Bharali, D. J., and Mousa, S. A. (2009). Cancer detection and treatment: the role of nanomedicines. Mol. Biotechnol. 42, 358-366. doi: 10.1007/s12033-009-9161-0

Lebedeva, I. V., Su, Z. Z., Vozhilla, N., Chatman, L., Sarkar, D., Dent, P., et al. (2008). Chemoprevention by perillyl alcohol coupled with viral gene therapy reduces pancreatic cancer pathogenesis. Mol. Cancer Ther. 7, 2042-2050. doi: 10.1158/1535-7163.MCT-08-0245

Lei, Y., Tang, L., Xie, Y., Xianyu, Y., Zhang, L., Wang, P., et al. (2017). Gold nanoclusters-assisted delivery of NGF siRNA for effective treatment of pancreatic cancer. Nat. Commun. 8, 15130. doi: 10.1038/ncomms15130

Li, R. J., Ying, X., Zhang, Y., Ju, R. J., Wang, X. X., Yao, H. J., et al. (2011). All-trans retinoic acid stealth liposomes prevent the relapse of breast cancer arising from the cancer stem cells. J. Control Release 149, 281-291. doi: 10.1016/ j.jconrel.2010.10.019

Li, H., Shi, L., Wei, J., Zhang, C., Zhou, Z., Wu, L., et al. (2016). Cellular uptake and anticancer activity of salvianolic acid B phospholipid complex loaded nanoparticles in head and neck cancer and precancer cells. Colloids Surf. B B. 147, 65-72. doi: 10.1016/j.colsurfb.2016.07.053

Locatelli, M., Tinari, N., Grassadonia, A., Tartaglia, A., Macerola, D., Piccolantonio, S., et al. (2018). FPSE-HPLC-DAD method for the quantification of anticancer drugs in human whole blood, plasma, and urine. J. Chromatogr. B 1095, 204-213. doi: 10.1016/j.jchromb.2018.07.042

Majumdar, D., Jung, K. H., Zhang, H., Nannapaneni, S., Wang, X., Amin, A. R., et al. (2014). Luteolin nanoparticle in chemoprevention: in vitro and in vivo anticancer activity. Cancer Prev. Res. (Phila) 7, 65-73. doi: 10.1158/19406207.CAPR-13-0230

Malatesta, L., Cosco, D., Paolino, D., Cilurzo, F., Costa, N., Di Tullio, A., et al. (2018). Simultaneous quantification of Gemcitabine and Irinotecan hydrochloride in rat plasma by using high performance liquid chromatography-diode array detector. J. Pharm. Biomed. Anal. 159, 192199. doi: $10.1016 /$ j.jpba.2018.06.060

Margulis-Goshen, K., Weitman, M., Major, D. T., and Magdassi, S. (2011). Inhibition of crystallization and growth of celecoxib nanoparticles formed from volatile microemulsions. J. Pharm. Sci. 100, 4390-4400. doi: 10.1002/ jps.22623

Meng, T., Qiu, G., Hong, Y., Yuan, M., Lu, B., Wu, J., et al. (2019). Effect of chitosan based glycolipid-like nanocarrier in prevention of developing acquired drug resistance in tri-cycle treatment of breast cancer. Int. J. Pharm. 555, 303-313. doi: 10.1016/j.ijpharm.2018.11.056

Mieras, A., Pasman, H. R. W., Onwuteaka-Philipsen, B. D., Dingemans, A. M. C., Kok, E. V., Cornelissen, R., et al. (2019). Is In-Hospital Mortality Higher in Patients With Metastatic Lung Cancer Who Received Treatment in the Last Month of Life? A Retrospective Cohort Study. J. Pain Symptom Manage. 58, 805-811. doi: 10.1016/j.jpainsymman.2019.06.026

Miller, M. S., Allen, P., Brentnall, T. A., Goggins, M., Hruban, R. H., Petersen, G. M., et al. (2016). Pancreatic Cancer Chemoprevention Translational Workshop: Meeting Report. Pancreas 45, 1080-1091. doi: 10.1097/ MPA.0000000000000705

Mitra, S., and Dash, R. (2018). Natural Products for the Management and Prevention of Breast Cancer. Evid Based Complement Altern. Med. 2018, 8324696. doi: 10.1155/2018/8324696

Monteillier, A., Voisin, A., Furrer, P., Allémann, E., and Cuendet, M. (2018). Intranasal administration of resveratrol successfully prevents lung cancer in $\mathrm{A} /$ J mice. Sci. Rep. 8, 14257. doi: 10.1038/s41598-018-32423-0

Morgen, M., Bloom, C., Beyerinck, R., Bello, A., Song, W., Wilkinson, K., et al. (2012). Polymeric nanoparticles for increased oral bioavailability and rapid absorption using celecoxib as a model of a low-solubility, high-permeability drug. Pharm. Res. 29, 427-440. doi: 10.1007/s11095-011-0558-7

Mukherjee, S., Ghosh, S., Das, D. K., Chakraborty, P., Choudhury, S., Gupta, P., et al. (2015). Gold-conjugated green tea nanoparticles for enhanced anti-tumor activities and hepatoprotection-synthesis, characterization and in vitro evaluation. J. Nutr. Biochem. 26, 1283-1297. doi: 10.1016/j.jnutbio.2015.06.003

Muqbil, I., Masood, A., Sarkar, F. H., Mohammad, R. M., and Azmi, A. S. (2011). Progress in nanotechnology based approaches to enhance the potential of chemopreventive agents. Cancers 3, 428-445. doi: 10.3390/cancers3010428

Naponelli, V., Ramazzina, I., Lenzi, C., Bettuzzi, S., and Rizzi, F. (2017). Green Tea Catechins for Prostate Cancer Prevention: Present Achievements and Future Challenges. Antioxid. (Basel) 6, pii: E26. doi: 10.3390/antiox6020026

Nie, S., Hsiao, W. L., Pan, W., and Yang, Z. (2011). Thermoreversible Pluronic F127-based hydrogel containing liposomes for the controlled delivery of paclitaxel: in vitro drug release, cell cytotoxicity, and uptake studies. Int. J. Nanomed. 6, 151-166. doi: 10.2147/IJN.S15057

Office On, S., and Health (2006). "Publications and Reports of the Surgeon General," in The Health Consequences of Involuntary Exposure to Tobacco Smoke: A Report of the Surgeon General. (Atlanta (GA): Centers for Disease Control and Prevention (US)).

Pan, P., Huang, Y. W., Oshima, K., Yearsley, M., Zhang, J., Yu, J., et al. (2018). Could Aspirin and Diets High in Fiber Act Synergistically to Reduce the Risk of Colon Cancer in Humans? Int. J. Mol. Sci. 19, pii: E166. doi: 10.3390/ ijms19010166 
Parashar, P., Rathor, M., Dwivedi, M., and Saraf, S. A. (2018). Hyaluronic Acid Decorated Naringenin Nanoparticles: Appraisal of Chemopreventive and Curative Potential for Lung Cancer. Pharmaceutics 10, 33. doi: 10.3390/ pharmaceutics 10010033

Patterson, S. L., Colbert Maresso, K., and Hawk, E. (2013). Cancer Chemoprevention: Successes and Failures. Clin. Chem. 59, 94. doi: 10.1373/clinchem.2012.185389

Pool, H., Campos-Vega, R., Herrera-Hernández, M. G., García-Solis, P., GarcíaGasca, T., Sánchez, I. C., et al. (2018). Development of genistein-PEGylated silica hybrid nanomaterials with enhanced antioxidant and antiproliferative properties on HT29 human colon cancer cells. Am. J. Trans. Res. 10, 2306-2323.

Prabhu, S., Kanthamneni, N., and Wang, J. (2007). Synergistic chemoprevention of colorectal cancer using colon-targeted polymer nanoparticles. Cancer Res. 67, 1-1.

Pulliero, A., Wu, Y., Fenoglio, D., Parodi, A., Romani, M., Soares, C. P., et al. (2015). Nanoparticles increase the efficacy of cancer chemopreventive agents in cells exposed to cigarette smoke condensate. Carcinogenesis 36, 368-377. doi: 10.1093/carcin/bgv008

Rahbarghazi, R., Jabbari, N., Sani, N. A., Asghari, R., Salimi, L., Kalashani, S. A., et al. (2019). Tumor-derived extracellular vesicles: reliable tools for Cancer diagnosis and clinical applications. Cell Commun. Signaling 17, 73-73. doi: 10.1186/s12964-019-0390-y

Rahman, F. A. U., Ali, S., and Saif, M. W. (2017). Update on the role of nanoliposomal irinotecan in the treatment of metastatic pancreatic cancer. Ther. Adv. Gastroenterol. 10, 563-572. doi: 10.1177/1756283X17705328

Ravikumar, P., and Tatke, P. (2019). Advances in encapsulated dermal formulations in chemoprevention of melanoma: An overview. J. Cosmet. Dermatol. 18, 1606-1612. doi: 10.1111/jocd.13105

Roy, J., Oliveira, L. T., Oger, C., Galano, J. M., Bultel-Ponce, V., Richard, S., et al. (2015). Polymeric nanocapsules prevent oxidation of core-loaded molecules: evidence based on the effects of docosahexaenoic acid and neuroprostane on breast cancer cells proliferation. J. Exp. Clin. Cancer Res. 34, 155. doi: 10.1186/s13046-015-0273-z

Sanna, V., Singh, C. K., Jashari, R., Adhami, V. M., Chamcheu, J. C., Rady, I., et al. (2017). Targeted nanoparticles encapsulating (-)-epigallocatechin-3-gallate for prostate cancer prevention and therapy. Sci. Rep. 7, 41573. doi: 10.1038/srep41573

Sarkar, F. H., and Li, Y. (2003). Soy isoflavones and cancer prevention. Cancer Invest. 21, 744-757. doi: 10.1081/CNV-120023773

Sarkar, S., Azab, B., Quinn, B. A., Shen, X., Dent, P., Klibanov, A. L., et al. (2014). Chemoprevention gene therapy (CGT) of pancreatic cancer using perillyl alcohol and a novel chimeric serotype cancer terminator virus. Curr. Mol. Med. 14, 125-140. doi: 10.2174/1566524013666131118110827

Shakeel, F., Haq, N., Al-Dhfyan, A., Alanazi, F. K., and Alsarra, I. A. (2015). Chemoprevention of skin cancer using low HLB surfactant nanoemulsion of 5fluorouracil: a preliminary study. Drug Deliv. 22, 573-580. doi: 10.3109/ 10717544.2013.868557

Shen, Z., Fan, W., Yang, Z., Liu, Y., Bregadze, V. I., Mandal, S. K., et al. (2019). Exceedingly Small Gadolinium Oxide Nanoparticles with Remarkable Relaxivities for Magnetic Resonance Imaging of Tumors. Small 15, e1903422. doi: 10.1002/smll.201903422

Shirode, A. B., Bharali, D. J., Nallanthighal, S., Coon, J. K., Mousa, S. A., and Reliene, R. (2015). Nanoencapsulation of pomegranate bioactive compounds for breast cancer chemoprevention. Int. J. Nanomed. 10, 475-484. doi: 10.2147/IJN.S65145

Siddiqui, I. A., Adhami, V. M., Chamcheu, J. C., and Mukhtar, H. (2012). Impact of nanotechnology in cancer: emphasis on nanochemoprevention. Int. J. nanomed. 7, 591-605. doi: 10.2147/IJN.S26026

Singh, P., Pandit, S., Mokkapati, V., Garg, A., Ravikumar, V., and Mijakovic, I. (2018). Gold Nanoparticles in Diagnostics and Therapeutics for Human Cancer. Int. J. Mol. Sci. 19, pii: E1979. doi: 10.3390/ijms19071979

Solomon, S. D., Mcmurray, J. J., Pfeffer, M. A., Wittes, J., Fowler, R., Finn, P., et al. (2005). Cardiovascular risk associated with celecoxib in a clinical trial for colorectal adenoma prevention. N Engl. J. Med. 352, 1071-1080. doi: 10.1056/NEJMoa050405

Song, Z., Feng, R., Sun, M., Guo, C., Gao, Y., Li, L., et al. (2011). Curcumin-loaded PLGA-PEG-PLGA triblock copolymeric micelles: Preparation, pharmacokinetics and distribution in vivo. J. Colloid Interface Sci. 354, $116-$ 123. doi: 10.1016/j.jcis.2010.10.024

Sulfikkarali, N., Krishnakumar, N., Manoharan, S., and Nirmal, R. M. (2013). Chemopreventive efficacy of naringenin-loaded nanoparticles in 7,12dimethylbenz(a)anthracene induced experimental oral carcinogenesis. Pathol. Oncol. Res. 19, 287-296. doi: 10.1007/s12253-012-9581-1
Sun, P., Huang, W., Jin, M., Wang, Q., Fan, B., Kang, L., et al. (2016). Chitosanbased nanoparticles for survivin targeted siRNA delivery in breast tumor therapy and preventing its metastasis. Int. J. Nanomed. 11, 4931-4945. doi: $10.2147 / \mathrm{IJN} . \mathrm{S} 105427$

Sutaria, D., Grandhi, B. K., Thakkar, A., Wang, J., and Prabhu, S. (2012). Chemoprevention of pancreatic cancer using solid-lipid nanoparticulate delivery of a novel aspirin, curcumin and sulforaphane drug combination regimen. Int. J. Oncol. 41, 2260-2268. doi: 10.3892/ijo.2012.1636

Tan, A., Davey, A. K., and Prestidge, C. A. (2011). Silica-Lipid Hybrid (SLH) Versus Non-lipid Formulations for Optimising the Dose-Dependent Oral Absorption of Celecoxib. Pharm. Res. 28, 2273-2287. doi: 10.1007/s11095011-0458-x

Testa, U., Pelosi, E., and Castelli, G. (2018). Colorectal cancer: genetic abnormalities, tumor progression, tumor heterogeneity, clonal evolution and tumor-initiating cells. Med. Sci. (Basel Switzerland) 6, 31. doi: 10.3390/ medsci6020031

Thakkar, A., Sutaria, D., Grandhi, B. K., Wang, J., and Prabhu, S. (2013). The molecular mechanism of action of aspirin, curcumin and sulforaphane combinations in the chemoprevention of pancreatic cancer. Oncol. Rep. 29, 1671-1677. doi: 10.3892/or.2013.2276

Thomasset, S. C., Berry, D. P., Garcea, G., Marczylo, T., Steward, W. P., and Gescher, A. J. (2007). Dietary polyphenolic phytochemicals-promising cancer chemopreventive agents in humans? A review of their clinical properties. Int. J. Cancer 120, 451-458. doi: 10.1002/ijc.22419

Tran, B. N., Nguyen, H. T., Kim, J. O., Yong, C. S., and Nguyen, C. N. (2017). Combination of a chemopreventive agent and paclitaxel in CD44-targeted hybrid nanoparticles for breast cancer treatment. Arch. Pharm. Res. 40, 14201432. doi: 10.1007/s12272-017-0968-0

Tyagi, N., De, R., Begun, J., and Popat, A. (2017). Cancer therapeutics with epigallocatechin-3-gallate encapsulated in biopolymeric nanoparticles. Int. J. Pharm. 518, 220-227. doi: 10.1016/j.ijpharm.2016.12.030

U.S. Preventive Services Task Force (2007). Routine aspirin or nonsteroidal antiinflammatory drugs for the primary prevention of colorectal cancer: U.S. Preventive Services Task Force recommendation statement. Ann. Intern Med. $146,361-364$.

U.S. Preventive Services Task Force (2016). Aspirin Use to Prevent Cardiovascular Disease and Colorectal Cancer: Preventive Medication, [Online] Available: https://www.uspreventiveservicestaskforce.org/Page/ Document/Recommendation Statement Final/aspirin-to-preventcardiovascular-disease-and-cancer [Accessed 2019/12/12]

Umezawa, S., Higurashi, T., Komiya, Y., Arimoto, J., Horita, N., Kaneko, T., et al. (2019). Chemoprevention of colorectal cancer: Past, present, and future. Cancer Sci. 110, 3018-3026. doi: 10.1111/cas.14149

Uramova, S., Kubatka, P., Dankova, Z., Kapinova, A., Zolakova, B., Samec, M., et al. (2018). Plant natural modulators in breast cancer prevention: status quo and future perspectives reinforced by predictive, preventive, and personalized medical approach. EPMA J. 9, 403-419. doi: 10.1007/s13167-018-0154-6

Vernon, S. W. (1997). Participation in Colorectal Cancer Screening: A Review. JNCI: J. Natl. Cancer Inst. 89, 1406-1422.

Wan, X., Zheng, X., Pang, X., Pang, Z., Zhao, J., Zhang, Z., et al. (2016). Lapatinibloaded human serum albumin nanoparticles for the prevention and treatment of triple-negative breast cancer metastasis to the brain. Oncotarget 7, 3403834051. doi: 10.18632/oncotarget.8697

Wang, J., Sun, X., Zhao, J., Yang, Y., Cai, X., Xu, J., et al. (2017). Exosomes: A Novel Strategy for Treatment and Prevention of Diseases. Front. Pharmacol. 8, 300-300. doi: 10.3389/fphar.2017.00300

Wei, Y., Wang, Y., Xia, D., Guo, S., Wang, F., Zhang, X., et al. (2017). Thermosensitive Liposomal Codelivery of HSA-Paclitaxel and HSAEllagic Acid Complexes for Enhanced Drug Perfusion and Efficacy Against Pancreatic Cancer. ACS Appl. Mater. Interfaces 9, 25138-25151. doi: $10.1021 /$ acsami.7b07132

Wong, K. E., Ngai, S. C., Chan, K.-G., Lee, L.-H., Goh, B.-H., and Chuah, L.-H. (2019). Curcumin Nanoformulations for Colorectal Cancer: A Review. Front. Pharmacol. 10, 152. doi: 10.3389/fphar.2019.00152

Wu, M., Wang, G., Hu, W., Yao, Y., and Yu, X.-F. (2019). Emerging roles and therapeutic value of exosomes in cancer metastasis. Mol. Cancer 18, 53. doi: $10.1186 /$ s12943-019-0964-8 
Zhang, L., Qi, Y., Min, H., Ni, C., Wang, F., Wang, B., et al. (2019a). Cooperatively Responsive Peptide Nanotherapeutic that Regulates Angiopoietin Receptor Tie2 Activity in Tumor Microenvironment To Prevent Breast Tumor Relapse after Chemotherapy. ACS Nano 13, 5091-5102. doi: 10.1021/acsnano.8b08142

Zhang, L. X., Sun, X. M., Xu, Z. P., and Liu, R. T. (2019b). Development of Multifunctional Clay-Based Nanomedicine for Elimination of Primary Invasive Breast Cancer and Prevention of Its Lung Metastasis and Distant Inoculation. ACS Appl. Mater. Interfaces 11, 35566-35576. doi: 10.1021/acsami.9b11746

Zubair, H., Azim, S., Ahmad, A., Khan, M. A., Patel, G. K., Singh, S., et al. (2017). Cancer Chemoprevention by Phytochemicals: Nature's Healing Touch. Mol. (Basel Switzerland) 22, 395. doi: 10.3390/molecules22030395
Conflict of Interest: The authors declare that the research was conducted in the absence of any commercial or financial relationships that could be construed as a potential conflict of interest.

Copyright (c) 2020 Desai, Thumma, Wagh, Zhan, Ann, Wang and Prabhu. This is an open-access article distributed under the terms of the Creative Commons Attribution License (CC BY). The use, distribution or reproduction in other forums is permitted, provided the original author(s) and the copyright owner(s) are credited and that the original publication in this journal is cited, in accordance with accepted academic practice. No use, distribution or reproduction is permitted which does not comply with these terms. 